\title{
ASPECTOS JURÍDICOS DA CONCEPÇÃO DE FAMÍLIA NA SOCIEDADE BRASILEIRA
}

\section{JURIDICAL ASPECTS OF THE CONCEPT OF FAMILY IN BRAZILIAN SOCIETY}

AOKI, L. P. S.; TARDELI, R. Aspectos Jurídicos da Concepção de Família na Sociedade Brasileira. Rev. Bras. Cresc. Des. Hum., São Paulo, IV(1), 1994.

Resumo: São apresentados, sob o ângulo jurídico, alguns aspectos fundamentais da concepção de fam1ia, tal como esta acabou impondo-se no contexto sócio-cultural brasileiro. Do ponto de vista sincrônico e diacrônico, foram destacados aspectos jurídicos das suas funções, do seu enraizamento antropológico e dos dilemas que, arraigados no passado, afetam a dinâmica da instituição familiar brasileira, nos dias de hoje.

Palavras-chave: concepção de fanu1ia, aspectos jurídicos, sincronia, diacronia.

Summary: Some basic juridical aspects of the concept of family are presented, as the family came to be imposed on the brazilian sociocultural context.

From a synchronic and from a diachronic perspective, the juridical aspects of its functions and of its anthropological roots were stressed, together with the juridical aspects of the dillemas that, originated in the past, affect the dynamics of the Brazilian family institution nowadays.

Key-words: concept of family, juridical aspects, synchronic, diachronic.

1 Promotor de Justiça do Fórum de Botucatu. END: Praça Rui Barbosa, s/n Botucatu - SP, CEP 18600-904 Fone: (0149) 220999 Fax: (0149) 22.0899

2 Promotor de Justiça em Exercício do Centro de Apoio Operacional das Promotorias de Justiça da Infância e da Juventudc c da Pessoa Portadora de Deficiência Física - Ministério Público do Estado São Paulo. END: Rua Líbero Badaró no $60014^{\circ}$ andar, São Paulo - SP, CEP 01008-908 Fone: (011) 232.0622 / 34.2150 Fax: 34.1374 
Relutamos por muito tempo, sobre como abordaríamos o tema Família, vez que, por reunir múltiplas facetas, correria-se o risco de torná-lo muito teórico, e distanciá-lo da realidade, ou atermo-nos apenas a uma outra de suas faces e mergulhar o leitor numa visão apenas parcial da questão. Tentaremos mesclar as experiências e sermos menos entediosos possível. A verdade é que o legislador pátrio, socorrendo-se de legislações mais antigas e tão zelosas, cuidou de desenhar o contorno de uma família, estipulando os papéis a serem desempenhados pelos seus membros, antes, durante e depois de sua existência, que aliás, raramente se extingue.

\section{ANOTAÇÃO À VIDA DO INDIVÍDUO, FORMADOR DA FAMÍLIA}

Assim é que, procurou proteger desde a sua concepcão o embrião que vive no ventre materno, e um dia constituirá parte de uma família (art. $4^{\circ}$ do Código Civil).

“A personalidade civil do homem começa do nascimento com vida; mas a lei põe a salvo desde a concepção os direitos do nascituro”.

Para isso, estabeleceu sanções penais severas, proibindo o aborto (artigos 124 a 127 do Código Penal).

\footnotetext{
"Provocar aborto em si mesma ou consentir que outrem Iho provoque”. (artigo 124) "Provocar aborto, sem consentimento da gestantc”. (artigo 125) "Provocar aborto, com consentimento da gestante^n. (artigo 1263 Parágrafo nico: "Aplica-se a pena do artigo anterior, se a gestante não é maior de 14 (quatorze) anos, ou é alienada ou débil mental, ou se o consentimento c obtido mediante fraude, grave ameaça ou violência”. "As penas cominadas nos dois artigos anteriores são aumentadas de um terço, se, em consequência do aborto ou dos meios empregados para provocá-lo, a gestante sofre lesão corporal de natureza grave; e são duplicadas, se por, qualquer dessas causas, Ihe sobrevém a mortes. (artigo 127)
}

E, admitindo-o em situações excepcionalíssimas (artigo 128 do Código Penal).

\footnotetext{
Não se pune o aborto praticada por médico: I - se não há outro meio de salvar a vida da gestante.

II - se a gravidez resulta de estupro e o aborto é precedido \& consentimento da gestante ou, quando incapaz, de seu representante legal".
}

No Estatuto da Criança e do Adolescente, cuidou-se meticulosamente desta protecão, estabelecendo inclusive a responsabilidade do Estado em assistir a gestante, enfatizando aproteção à vida e à saúde, mediante efetivacão de políticas sociais públicas que permitam o nascimento e o desenvolvimento sádio e harmonioso, em condições dignas de existência (artigo 7 do ECA).

Preocupou-se também em prevenir a ocorrência de anormalidades no metabolismo do recémnascido, determinando a obrigatoriedade da realização de exames visando o diagnóstico precoce e a indicação de terapêutica adequada, incluindo aí, a orientação aos pais (artigo 10, m do ECA).

Esta proteção à vida do bebe, tão necessária para a formação de um indivíduo saudável, mostra a preocupação do legislador em garantir uma nação formada por seres melhor cuidados, desde o ventre materno.

\section{SURGIMENTO}

Não há no caso presente o dilema de saber quem nasceu primeiro, o indivíduo ou sua família, posto que, esta é uma aquisição cultural, que não existia nos primórdios da civilização, onde a vida grupal, do bando ou clã, superavam a noção de família, como hoje a temos.

Poderiamos dizer, sem sombra de dúvida, que o conceito de família alterou-se ao longo do tempo, tanto quanto o próprio indivíduo.

E o direito, como ciência disciplinadora das relações sociais, acaba absorvendo entre os "usos e costumes as inovações que mais firmemente se enraizam no dia a dia do individuo, e que, por si só, imprimem nova faceta à vida social, independentemente de ter um regramento próprio a discipliná-lo.

Assim tem sido, em especial, no caso afamflia, cuja existência independeu sempre do reconhecimento juridico, desde quando começou a dar seus primeiros passas, nos primórdios da civilização humana, onde rudimentarmente se reconhecia como membro deste conceito aquele nascido da mesma mulher, já que "a maternidade era sempre certa".

Com o passar dos tempos, e ante a necessidade da força para a proteção do grupo tribal, ampliou-se o conceito de família, incluindo-se nele todos aqueles que se achavam dominados e amparados pela mesma força. 


\section{UM POUCO DE ANTROPOLOGIA}

Etimologicamente, o vocábulo português e o espanhol^^amilia é empréstimo erudito, provavelmente por via eclesiástica, ao latim, família, "conjunto de escravos e servidores de uma pessoa”, assim família, derivado de famülus, "servidor, escravo"; documentado em espanhol e português já no século IV. O francês^^famile é do século XIV e o inglês family do inicio do século XV.

Embora nas sociedades ocidentais o conceito de família esteja predominantemente ligado à idéia de um casal e seus filhos, a verdade é que a antropologia, quer em sua análise sincrônica, dos mais diversos grupamentos humanos, em sociedades simples ou tribais, quer por um estudo diacrônico, seja histórico, da sociedade ocidental, revelou que os conceitos de família e parentesco não são os mesmos em todas as sociedades.

A família existente à época do feudalismo diferia tanto da que existe atualmente, quanto da família patriarcal do Brasil Colônia, assim como, segundo José de Anchieta permite-nos avaliar hoje, divergiam profundamente os conceitos de paternidade e maternidade adotados pelos Tupinambás daqueles que adoramos hoje:

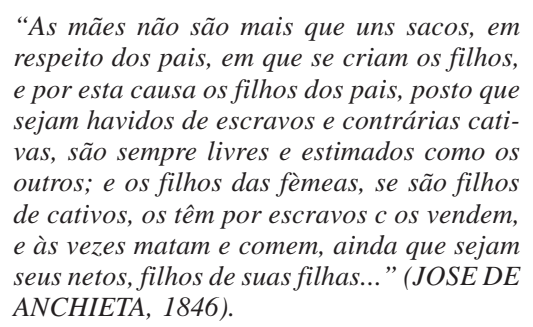

“As mães não são mais que uns sacos, em respeito dos pais, em que se criam os filhos, e por esta causa os filhos dos pais, posto que sejam havidos de escravos e contrárias cativas, são sempre livres e estimados como os outros; e os filhos das fèmeas, se são filhos de cativos, os têm por escravos c os vendem, $e$ às vezes matam e comem, ainda que sejam seus netos, filhos de suas filhas..." (JOSE DE ANCHIETA, 1846).

Mais do que relações puramente biológicas, família e parentesco constituem feixes de relações sociais, não constituindo meras entidades abstraias e estáticas.

Daí porque, a diferenciação encontrada pela antropologia no conceito de pater e genitor, isto é, em grande número de sociedades tribais, onde o genitor, o pai biológico, nem sempre exerce o papel que, na nossa sociedade consideramos ser o papel do pai, que será desempenhado, ali, por outro homem, que pode ser por exemplo o irmão da mãe. EVANS-PRITCHARD (1940) notou entre os Nuer da África uma instituição por ele denominada "casamento fantasma", consistente no dever de um parente mais próximo se casar com uma mulher em nome daquele que morre antes que se conclua os preparativos para o seu casamento, ou tem apenas filhas, ou seus filhos morrem antes de crescer, sendo que os filhos desse casamento fantasma serão socialmente reconhecidos como filhos do primeiro homem.
A antropologia atual busca determinar os princípios básicos de estruturação que permanecem os mesmos nas diferentes sociedades, apesar de encobertos por aparente diversidade.

Para MURDOCK (1960), a família é um grupo social caracterizado por residência comum, cooperação económica e reprodução. Reconhece-se à família quatro funções fundamentais: a sexual, a económica, a reprodutiva e a educacional. A primeira e a terceira são importantes para a manutenção da própria sociedade, a segunda para a manutenção da vida, e a quarta para a manutenção da cultura Essas funções, entretanto, não são as únicas desempenhadas pela família. Ela freqüentemente (embora não universalmente) abrange outras funções, entre as quais, por exemplo, pode ser o centro do culto religioso, e o status social de um indivíduo pode depender da posição social da família mais do que de seu valor, além do que, as quatro funções sociais básicas, podem ser desempenhadas por agentes e instituições situadas fora da família.

Murdock e Lowie consideram a família nuclear, constituída de pai, mãe e filhos, como um agrupamento humano universal.

Segundo LOWIE (1911): “...não importa se as relações maritais são permanentes ou temporárias, se há poligamia, poliandria ou licença sexual; se as condições se complicam pela adição de membros não incluídos no nosso círculo familiar: o único falo que aparece acima de todos é que, em todo lugar, marido, mulher e filhos constituem uma unidade à parte do resto da comunidade". Tem-se assim que a família nuclear é a unidade a partir da qual famílias extensas são constituídas.

Para MURDOCK (1960), mesmo que formas mais complexas de famílias possam existir e mesmo que essas unidades assumam algumas tarefas da unidade menor, a família nuclear é sempre reconhecível e sempre tem suas funções distintivas e vitais. Para este autor, a família nuclear é uma unidade de utilidade social, e que sua universalidade não deve ser buscada só em suas funções como coletividade, mas nos serviços e satisfações das relações entre seus membros.

Na verdade, a família define-se não somente pela união sexual de um homem e uma mulher, mas também pela cooperação económica entre seus membros. Esses dois falares devem estar sempre associados; isso porque existem inúmeras sociedades onde as relações sexuais não estão interditadas fora do casamento, e por outro lado, a cooperação económica entre um homem e uma mulhe^I pode também ser encontrada fora do casamento, coma ocorre, por exemplo, entre um irmão e uma irmã 
A idéia de universalidade da famDia nuclear foi contestada por diversos autores. Levy e Fallers acham importante a distinção entre famDia como um grupo concreto e como um grupo complexo de relações da família nuclear. Sob esse último prisma, pode-se ver que o comportamento apropriado a cada um dos papéis deste complexo pode estar distribuído entre um número de individuos ou agentes que não constituem um único grupo. MALINOWSKI (1949) por exemplo, relata que observou em Trobriand o exercício do papel que se espera seja desempenhado pelo pai (em nossa sociedade), sendo desempenhado pelo irmão da mãe. Por isso, ao se falar em complexo das relações da família nuclear, podese considerá-lo presente em todas as sociedades humanas.

Com a necessidade de sistematizar a ramificação dos laços de parentesco resultante do tabu do incesto, a sociedade teve que cuidar da definição de prioridades, isto é, definir o grupo de parentes de um individuo que deve ser privilegiado no que diz respeito a ajuda material, serviços cerimoniais, etc..

A solução deste problema é encontrada através da adoção de uma regra de descendência, que filia o individuo, ao nascer, a um grupo particular de parentes, do qual ele é especialmente íntimo, e pode esperar certos tipos de serviços, que não pode pedir a não parentes ou mesmo a outros membros da família. As regras de descendência são em número de quatro: patrilinear, que filia uma pessoa através dos homens de um grupo; matrilinear, que filia uma pessoa através das mulheres de um grupo; e bilateral ou multilateral, que filia uma pessoa a um grupo de parentes próximos a ela, independentemente de sua conexão genealógica particular, e finalmente a descendência dupla ou bilinear, que localiza os indivíduos em um grupo de cada tipo, valendo observar que as regras de descendência referem-se somente a fixação social, como por exemplo, a filiação em grupos discretos corporados com propósitos rituais, heranças', casamentos, etc..

$\mathrm{O}$ desenvolvimento dos estudos sobre a família, e a preocupação com os estudos de parentesco (e conseqüentemente, da famDia), como um dos aspectos da organização social, foi iniciada, pode-se dizer, com a publicação do trabalho Systems of consaguinit and afia nity de Morgan, na segunda metade do século XIX. Embora outros autores houvessem tratado do assunto, como M'LENNAN (1865), a importância de Morgan reside no falo de ter sido ele próprio o observador, pela convivência que teve com um grupo primitivo, enquanto que os seus antecessores baseavam-se em relatos de viajantes, missionários e funcionários coloniais, ou documentos.
Englers encampou as idéias de Morgan e escre veu mais tarde Der Ursprur $\sim g$ der Familie, dei Privateigentums und Staates, concluíndo que o sistema estável da famDia monogarnica, dominado pela autoridade masculina e sustentado pela lei, desenvolveuse como suporte da propriedade privada KROEBER (1969) contestou a divisão feita $\mathrm{p}$

Morgan entre sistemas de parentesco classificatórios e sistemas de parentesco descritivos, afirmando que nada é mais precário do que deduzir a existência de instituições sociais através das designações de parentesco, que são, antes de tudo, expressão psicológica e não sociológico Por sua vez, essa posição foi criticada por Rivers, em sua obra Kinship and social organization onde procura demonstrar a conexão entre o método de denominar parentes e as formas de organização social, ressaltando-se a sua importancia pelo fato de haver regulamentado a aplicação do método genealógico, instrumento mínimo| de trabalho do antropólogo.

Hocart considera a tradução inadequada dos termos de parentesco como 0 principal obstáculo à compreensão efetiva do sistema de parentesco.

RADCLIFFE (1924) criticou o método histórico conjecturar, considerando que o acesso à verdade histórica seria extremamente útil ao antropólogo, mas que isso não é possível porque o seu campo de estudo são as sociedades ágrafas, desprovidas de qualquer documenta- I ção histórica. Encarou a família em termos de obrigações formais entre seus membros e entre estes e outros grupos. Para ele, “a nomenclatura de parentesco é o reflexo fiel das relações jurídicas que ocorrem entre os parentes próximos e distantes em cada tribo".

LEACH (1961), já contemporâneo, critica 0 uso inadequado do método comparativo em antropologia, considerando-o muito mais apropriado para a zoologia c a botanica do que para a antropologia, já que antropólogos lidam com um conjunto de variaveis e não de coisas. Postula, dai, uma abordagem matemática, que seria a única capaz de fornecer à antropologia os recursos necessários à compreensão dessas variaveis. Acha também que Fortes errou, como Malinowski, ao criar o conceito de "paternidade sociológico" para os trobiandeses, considerando-os imbuidos de um preconceito da nossa sociedade, que admite a priori, a existência de algo semelhante a pai em qualquer sociedade.

A obra de LÉVI-STRAUSS (1958) é considerada também marco para os estudos de parentesco e mitologia na antropologia social. Em Antropologie structurale diz textualmentc: "É claro que a farnilia biológica existe em todas as sociedades. Mas, o que confere ao parentesco seu caráter sócio-cultural não é o que ele retém da natureza, mas o modo essencial pelo 
qual ele diverge dela. Um sistema de parentesco não consiste em laços objetivos de descendência ou consangüinidade entre indivíduos... a essência do parentesco humano é requerer o estabelecimento de relações entre o que Radcliffe Brown chama "faniilias elementares". Logo, não são as famílias, (termos isolados) que são elementares, e sim as relações entre esses termos”.

O surgimento de clãs foi o passo seguinte, e na sequência as estirpes, as dinastias, etc..

Houve periodos, sem dúvida, em que o sentimento de pertencer a uma família, equiparava-se aos principais valores éticos e sociais, dai a importancia que se deu à deserdacão, à semelhança do banimento de um elemento do grupo tribal, expondo-o praticamente à morte, vez que assim, ficaria à mercê das feras e dos inimigos daquela tribo.

Contudo, com o passar dos anos, e o surgimento de novas expectativas de vida, a necessidade de expansão económica, mesclaram-se aos costumes, pela própria necessidade de adaptação do homem ao novo meio em que fora obrigado a conviver.

Sem nos determos nos episódicos casos de romance entre famílias de inimizades figadais, que se tornaram célebres na história, provocando muitos deles, verdadeiras guerras entre reinas e nações, a mudança cultural veio ser acelerada com as migrações além mar dos europeus. Em consequência disso, os padrões e conceitos familiares nas culturas delas derivadas alteraram-se mais fortemente do que os conceitos originários das culturas orientais, resultando dai, a permanência de estruturação do grupo familiar muito mais fortemente naqueles países asiáticos ou povoados por descendentes destes, do que nas civilizações povoadas e dominadas pelo elemento europeu que em maior número migrou.

Fácil é perceber que o migrante europeu, por ter que se distanciar de sua família de origem, embrenhando-se além mar, e aqui, nas imensas florestas tropicais, acabou por constituir outro núcleo familiar, que originou família tão respeitada quanto àquela originária, muitas das quais, nunca mais vistas ou relacionadas com o chefe do clã.

Esta fissura na organização familiar, permitindo a reconstrução de novo grupamento familiar, tão forte e respeitado quanto o primeiro, parece ser o embrião do divórcio dos tempos atuais, que no Brasil, em especial, demorou a ser reconhecido legalmente, ante a obstinada rejeição que se fazia à sua admissão pelas instituições mais conservadoras.

\section{A DELICADA CONSTITUIÇÃO DE UM GRUPO FAMILIAR}

Detemo nos um pouco aqui para refletir num elemento circunstancialmente muito importante e que, por sua delicadeza de definição de seus contornos, não teve como ser abordada legislativamente.

Falamos da delicada constituição de um grupo familiar, ou seja, a junção de dois seres oriundos de dois grupamentos diferentes, com hábitos, génios, ideologias, costumes, níveis económicos e sociais, às vezes até interesses religiosos, políticos, culturais, etc., que por uma mágica que escapa à lógica do mais avançado computador já conhecido, resolvem se unir.

Procurou o legislador estabelecer a idade propícia para isso, vedando assim o casamento da mulher antes dos dezasseis anos e do homem antes dos dezoito anos (art. 183, inciso XII do Código Civil); bem como aqueles elementos cujo parentesco próximo pudessem facilitar uma malformação genética de seus descendentes (art. 183, inciso I e IV do Código Civil); ou ainda aqueles que estivessem em peculiar relação familiar, como é o caso dos parentes afins em linha rota, 0 adorante com 0 cônjuge do adotado e vice-versa, o cônjuge adúltero com o seu co-réu, por tal condenado, o cônjuge sobrevivente com o condenado como delinquente no homicídio ou tentativa de homicídio contra o seu consorte, (art. 183, incisos Il, III, VII, VIII); ou ainda, em razão de uma determinada situação especial entre as partes, como por exemplo, as pessoas por qualquer motivo contas, e as incapazes de consentir ou manifestar de modo inequívoco o seu consentimento, o raptor com a raptada, enquanto esta não se ache fora do seu poder, os sujeitos ao pátrio poder, tutela, ou curatela, enquanto não for suprido o consentimento (art. 183, incisos IX, X, XI do Código Civil).

Todavia, o que nos chama mais a atenção no diaa-dia, e que, por mais esforço que adotemos, raramente é levado na devida consideração, é a preparação para a formação de uma família.

Se não podemos quantificar valores e dados abstratos como sentimentos, amor, paixão, etc., é certo que, alguns outros elementos, bem mais concretos e perceptiveis, podem ser quantificados, e nem estes são avaliados ponderadamente na apressada formação de uma família, nem mesmo por aqueles casais mais "maduros", que por um tempo mais longo "namoraram" antes de se decidirem pelo casamento.

Assim, se para reconhecermos apto para o desempenho de uma função em nosso meio, exigimos de um indivíduo, no mínimo dezasseis anos de educação escolar, preparando-o especificamente para desenvolver sua atividade profissional num campo específico, contentamo-nos com alguns minguados meses, e às vezes, raros 
anos de relacionamento entre dois seres, que já frisamos, apresentam-se provenientes de dois núcleos diferentes, para celebrar o mais solene dos contratos previstos no Código Civil.

E assim, preparam-se muitos para o casamento e alguns poucos para a formação de uma família.

É certo que é possível prever-se o regime de bens, o uso ou não do nome do futuro marido, a concordância com o local onde se fixará o domicilio da família, contudo, como esta será, somente Deus sabe.

Sim, porque no conjunto de reações, sentimentos e emoções, sutilmente encobertos à época do namoro pelo fascínio da descoberta do outro e de sua conquista, embaçados pelas expectativas de realização de uns quantos sonhos e ideais a dois, e enebriados pelo ardente despertar da atração sexual, muito dificilmente se ache alguém capaz de planejar sua família.

E deste modo, verdadeiramente, sem qualquer preparação maior do que, algum dado muito aleatório sobre o número de filhos, e quando raramente possível, a época em que estes deverão chegar, afoitamente se inicia uma família.

E diante disso, o Estado reconhece como família, tanto a união estável entre um homem e uma mulher, como qualquer deles e seus descendentes (art. 226, parágrafos $3^{\circ}$ e $4^{\circ}$ da Constituição Federal).

Por outro lado, cresce dia-a-dia o número de jovens grávidas neste pais, as quais, além da pouca idade reunem também quase nenhuma formação profissional, nem patrimonial, agregandose, quando podem, à família originária, que acaba assim, assumindo a nova vida que dali brota, sem que a participação do parceiro se possa notar constante, adequada, suficiente ou razoável para permitir o desprendimento daquela jovem e seu rebento.

Enveredamos então, pensamos nós, num dos mais conflitantes segmentos de uma relação familiar, qual seja, a necessidade de sustentação à distancia

Previsto como obrigação dos pais, mesmo quando não compostos dentro de um casamento, o dever de sustento da prole (art. 231, inciso IV do Código Civil), tem originado contendas dia cilimas, que se arrastam anos a fio pelos Fóruns e Tribunais deste pais.

A relação familiar, muito mais do que contratual, exacerba-se e desgasta-se, sem dúvida nenhuma em razão da grande proximidade de seus membros, do cotidiano vivido por estes, e pela pouca proteção que se tem na revelação dos sentimentos mais íntimos entre as partes.

Aliado a isto, acresce-se a monotonia desta relação, que raras vezes se preocupa em ser trabalhada e lapidada, evitando-se o fastio de recair-se sobre situações normalmente dolorosas para seus membros, repetindo-se então agressão pretérito, sobre machucado nem sempre já curado, permitindo assim a abertura de profundas chagas, que não têm previsão legal de serem contidas.

E então, a rotina está para o amor, sentimento mais nobre entre nós seres humanos, na mesma proporção que a ferrugem está para o ferro, o mais duro e resistente dos metais, corroendo a mais forte e aparente duradoura relação amorosa existente entre dois ou mais seres humanos.

Descuidada disso, vive a maior parte da população, e obviamente sofre os revezes deste seu descuido, pagando um preço muito alto para tal imprudência

Ocorre então a desagregação e amontoamse nos Fóruns os pedidos de pensão alimentícia, que na realidade seriam no mi^liimo um dever de solidariedade humana a ser prestado entre parentes, e de resolução fácil, se não estivessem envoltos em delicadas situações de agressivi\&ade não resolvidas entre precipitados e feridos amantes.

Juntamente com estes pedidos, muitas vezes até conjugadamente, crescem as discussões sobre a guarda e o direito de visita aos filhos.

Dolorosa e íngreme via percorrem todos, as partes envolvidas (pai, mãe e filhos), e também magistrados, promotores de justiça e corpo de serviço social (psic610gos e assistentes sociais), quando têm que se debruçar sobre tais casos, posto que, na ponta extrema da questão balouçam frágeis e muito pouco respeitadas as crianças e jovens, que sé recentemente tiveram o sagrado direito de exigir serem consultadas a respeito (artigo 28, parágrafo $1^{\circ}$ do ECA).

Para piorar a situação, temos casos, e muitos, onde as crianças e jovens adolescentes, buscam poder ver e visitar os próprios pais, posto que estes, alienados ao grave prejuízo que causam àqueles seres em formação, descuidam ou até mesmo rejeitam tal relacionamento.

\section{UM NOVO DIREITO}

Entrevemos agora, com o advento do Estatuto da Criança e do Adolescente, a possibilidade de exercerem as crianças e jovens, igual direito que tinham seus pais, de demarcar dia, hora e local para realizarem suas visitas, valendo-se da previsão legal contida no artigo $4^{\circ}$ do ECA.

\footnotetext{
Artigo $4^{\circ}$ - "É dever da família, da comunidade, da sociedade em geral e do Poder Público, assegurar, com absoluta prioridade, a efetivacão dos direitos referentes à vida, à saúde, à alimentac,ão, à educação, ao esporte, ao lazer, à profissionalização, à cultura, à dignidade, ao respeito, à liberdade c à convivência familiar e canunitária”.
} 
A simples conjugação dos itens acima destacados dá clara idéia do compromisso gerado pelo legislador, assegurando o direito da criança e do adolescente de pleitear, até mesmo em juízo, o respeito e a efetivação do seu direito de convivência familiar.

Ora, se compete à família, e ao Poder Público assegurar a efetivação deste direito, resulta disto que pode ser exigido judicialmente o cumprimento desta obrigação, pela parte interessada, ou seja, a criança e o adolescente, impondo-se por outro lado, o dever do Estado garantir esta efetivação, através dos meios disponíveis, ou seja, se necessário, até a condução coercitivo, posto que, agora, há mandamento legal a autorizar tal conduta.

Por outro lado, prevê o artigo 129, incisos III e IV a possibilidade de aplicar-se aos pais as medidas de "encaminhamento a tratamento psicológico ou psiquiátrico, e o encaminhamento a cursos ou programas de orientação", que, naturalmente poderão cuidar de estabelecer condições para que este convívio possa ser salutar para todos os envolvidos.

Assim, de igual modo, como hoje usualmente pleiteiam os pais o direito de visitar os filhos, podem agora os filhos, com o advento do Estatuto da Criança e do Adolescente, também pleitear o direito de visitar e serem visitados, conviver mesmo com os pais, numa forma de restabelecimento da convivência familiar.

Nota-se assim, grande avanço e interesse na preservação dos laços familiares o que representa um curvar-se à evidência de que, mais do que a célula base da sociedade, tem a família a correspondente função de marcar a temperatura de qualidade de vida desta sociedade, ainda que econômica e financeiramente progrida, não pode ufanar-se deste progresso quando cobra o preço alto do esfacelamento do grupo familiar, porque daí advém rupturas sociais tão graves ou mais graves do que a própria pobreza econômica pode provocar.

\section{NOVOS TEMPOS, VELHOS HÁBITOS}

No Ano Internacional da Família decretado pela Organização das Nações Unidas (ONU), abre-se uma excelente oportunidade para se debruçar sobre este tema, e rever conceitos, e repensar objetivos, e buscar soluções que, no passar dos anos, foram sendo improvisadas diante das transformações que irrompiam no dia-a-dia.

Não resta dúvida que se trata de tarefa delicada e espinhosa, pois, diferentemente de outros tantos tipos de questões, não se toca aqui apenas num indivíduo, mas num conjunto de indivíduos, que já se acham ajustados a um determinado papel representativo dentro do grupo familiar o qual, muitas vezes inclusive, nem mesmo é escolhido ou aceito, porém, forçosamente imposto e de difícil transformação, além de envolver relações emocionais que podem perpetuar-se geração a geração, sem muita lógica e explicação, e que, nem uma legislação mais avançada e interessada na recuperação deste núcleo institucional, poderia reverter um processo cancerígeno ali instalado.

Então, curvamo-nos diante do insólito e imponderável, e ainda que valendo-nos de conhecimentos científicos amealhados ao longo dos tempos, precisamos ainda acreditar que se não houver amor, teremos apenas um ajuntamento de pessoas, ligados ou não por vínculos de consangüinidade, que se pode chamar até de família, mas será verdadeiramente uma Família?

\section{PASSADO, PRESENTE E FUTURO}

\section{Como era antes}

A questão da família, no direito brasileiro, recebeu inicialmente na formulação dos civilistas tratamento quase subsidiário, verdadeiramente decorrente de uma relação jurídica que lhe antecedia necessariamente: o casamento. Era o patrimônio a matriz que gerava as relações familiares, não se contemplando a hoje chamada união livre ou concubinato, postos quase em situação de ilegalidade, sendo certo que o direito dos concubinos foi fruto de construção pretoriana ao longo das décadas deste século, até seu reconhecimento pela Constituição Federal de 1988.

Assim, a convivência familiar nada mais era que a decorrência de um dos deveres do casamento: a mútua assistência. A prole advinda consistia na finalidade maior do casamento. A família, enquanto célula social, não recebeu do direito positivo atenção especifica. Por razões históricas, confiou-se ao homem a função gerencial dos interesses dos filhos e da esposa, que, segundo a formulação originária, perdia, inclusive, parte de sua capacidade civil rebaixada ao status de semi-imputável, situação somente abrandada quase meio século depois, com o advento do Estatuto da Mulher Casada, em 1962. Mas, mesmo assim, a família em si considerada permanecia tangencialmente contemplada, sempre como pano de fundo da instituiçãomatriz, que era o casamento.

Se tudo dele era consectário, ao legislador de 1916, também o eram os próprios filhos, destinatários, por certo, da atenção e proteção dos pais, mas privados de vontade, no sentido especificamente jurídico do vocábulo Os filhos tinham - e ainda têm - os bens administrados pelos pais, aparecendo na maior parte das vezes como figuras também decorrentes do casamento. 
Tanto o eram que o Código Civil estabelecia verdadeira hierarquia entre filhos, enaltecendo os legítimos, frutos da relação matrimonial, indo até os espúrios, nascidos de clandestino relacionamento sexual. Tão evidente era a situação, qual seja, a de que a própria filiação subordinava-se à relação matrimonial que a extirpe da filiação encontrava-se subordinada à origem do filho. Desta forma, eram legítimos somente aqueles resultantes do casamento, que pairavam superiores aos naturais, aos ilegítimos e, finalmente, aos espúrios, que sequer direito ao nome possuíam. Ao lado destes, gravitava uma classe de subfilhos, oriundos de parentesco civil, isto é, os adotivos, cujo parentesco não ultrapassava o adorante, criando-se uma curiosa situação em que o filho não era neto do pai daquele que o adorara. Para afastar dúvidas acerca de sua origem, cuidava-se de atestar a linhagem e, na própria certidão de nascimento da criança, sua patente, haveria de ser eternizada (Fulano de Tal, filho legítimo de Beltrano e Sicrana).

Decorrentes que eram do matrimônio, sequer assistiam aos filhos direitos próprios da pessoa humana, por exemplo, o direito à intangibilidade física, de vez que era - e para muitos e respeitados autores ainda é - dado aos pais o direito de castigar moderadamente o filho.

Formulação burguesa por excelência, o Código Civil Brasileiro ainda se ressentia dos bafejes do Estado Religioso, característico do Império recentemente sepultado pela República, mas ainda presente na formação dos juristas de então, razão por que o casamento era condição necessária e suficiente para existência e estabelecimento da família. A família natural não existia, naqueles tempos em que a(o) concubina(o) era $\mathrm{a}(\mathrm{o})$ destruidora(o) dos lares constituídos.

Conquanto decorrência de uma relação jurídica anterior - o casamento - sequer se preocupou o legislador civil em conceituar a família, enquanto ente jurídico, limitando-se a descrever os deveres decorrentes do matrimônio e os deveres dos pais máximo o varão - relativamente à pessoa e aos bens dos filhos. A família não mereceu disciplina jurídica própria, nada obstante, sua reconhecida fonte de relações jurídicas, que lhe era inerente.

Causaria espécie ao legislador d'antanho se questionar sobre a necessidade da formulação de um direito que, libertando-se da condição de coadjuvante de uma instituição - o casamento - passasse a existir por si próprio. Certamente, teria aquele legislador dificuldades para compreender o direito à convivência familiar, com suas conseqüências específicas. Imaginamos que perplexidade lhe provocaria o reconhecimento da família natural.

A lacuna, como não poderia deixar de ser, começava a produzir perplexidades. Tornou-se impossível deixar de reconhecer que a família natural, ou seja, a célula comunitária composta por pessoas unidas com prole, mas sem os laços do casamento, compunha como ainda compõe a grande maioria das relações domésticas seu qualquer proteção jurídica. O concubinato começava importunar os Tribunais obrigando os operadores do $\mathrm{M}$ feito a elaborarem construções teóricas, que viessem rninimamente, responder as questões próprias do Direita de Família - pensão alimentícia, meação de bens, guarde de filhos e direito de visitas. Uma família, sem sê-lo ao olhos da lei, reclamava seu reconhecimento. Em suma reclamava sua visualizarão.

Foi árdua a evolução pretoriana, isto é, a evolução da interpretação do Direito Positivo pelos Tribunais Superior Instância, notadamente no que diz respeito ao reconhecimento e abrigo da família natural.

\section{Como é agora}

Com o advento da nova ordem constitucional, inaugurada pela Constituição Federal de 1988, foi notável avanço jurídico do tratamento recebido pela família, que passou a ser reconhecida base da sociedade (art. 226 caput). Se no preâmbulo da Carta Constitucional inscreveu-se que o fundamento da formulação da Constituição é a construção de uma sociedade fraterna, pluralista, sem preconceitos, bem se está a ver que, como nunca, dantes, à família consagrou-se verdadeiro enaltecimento avançando-se no reconhecimento da família natural conceituando a família como sendo a comunidade formada por qualquer dos pais e seus descendentes (art 226, par. $4^{\circ}$ ), promovendo-se a igualdade entre os cônjuges (art. 226, par. $5^{\circ}$ ).

Ao leitor desatento pareceria que a Constituição Federal fez pouco. Mas, fez muito e o avanço é digno dá todos os elogios, ainda que se discuta o conceito dá família, eleito pelo legislador constituinte originário. Se o significado, além do conceito, foi o de olhar, com olho de ver, para uma realidade que se tornava inelutável: c necessidade de se conceber a família, não mais como decorrência de um outro instituto jurídico, mas de si reconhecer a família como uma fonte de direitos, com luz e brilho próprios, com delineamento jurídico próprio do qual decorrerão outras conseqüências, que lhe serão iminentes, dentre as quais se destacam:

- o direito à convivência familiar - será interessante observar como os Tribunais o interpretarão, eis que se existe o direito à convivência da família, na outra face da moeda existirá o dever dessa mesma família - entenda-se pai e mãe de propiciar esse convívio, não sendo de se afastar o dever jurídico da visitação pelos pais ao filho, esteja ele internado em entidade de abrigo ou, excepcionalmente, em companhia de família substituta. 
- interessante inovação, já de longa data reconhedda àqueles casais que convolaram matrimónio, foi a possibilidade de verificada a hipótese de maus tratos, opressão ou abuso sexual impostos pelo pai ou responsável, a autoridade poderá determinar, como medida cautelar, o afastamento do agressor da moradia comum (art. 130, ECA). Anteriormente, a vítima do abuso era sempre duplamente penalizada, pelo abuso sofrido e com sua retirada do lar, lá permanecendo, não poucas vezes impune, o autor da agressão. Doravante, é afastado o agente desagregador da família, exatamente em obediência ao princípio do direito à convivência familiar.

- reconhecendo a família com fundamento da sociedade, enuncia a lei menorista que a falta ou carência de recursos materiais não corlstih^li motivo sufi ciente para suspensão do pátrio-poder. Falta de recursos significa ausência; carência nos indica a insuficiência dos recursos existentes. Se no passado, aos miseráveis não se garantia o direito à mantença da prole, atualmente a lei o reconhece, em nome do principio fundamental - o direito à convivência familiar - e, mais que isso, permite à comunidade organizada que acione o Poder Público para inclusão do grupo familiar em programa oficial ou comunitário de prote,cão à família (art. 129, inciso I).

- investindo no fortalecimento dos laços dafamilia, sempre em respeito ao direito à convivência familiar e comunitária, prevê a lei a criação de programa of cial ou comunitário de auxílio, orientação e tratamento a alcoólatras ou toxicómanos (artigo 129, II).

- sem se deixar seduzir por soluções simplistas, a existência do direito à convivência familiar liberto das amarras do sistema anterior e evoluindo de uma condição de coadjuvante ao status de direito próprio, em concerto, é verá, com outros, decorrentes de uma premissa inicial de proteção integral à infancia e juventude, admite-se a adoção como medida sempre excepcional, envelhecendo os discursos demagógicos que tratavam a adoção como solução de política pública.

\section{BIBLIOGRAFIA}

ANCHIEIA, J. Informações dos casamentos dos Indios. Rev. 1 Hist. Gea atual Rev. Inst. Geog. Bras., 8,1846.

BEVILAQUA, C. Direito e família. Rio de Janeiro, 1938.

CÓDIGO CIVIL, Lei no 3071, 01.01.1916.

CÓDIGO PENAL., Lei nº 2848, 07.09.1940.

\section{Olhando para o futuro}

A lei está posta. Seria, deveras, contraproducentc que a lei da menoridade viesse espelhar aquilo que é, ou seja, viesse tão somente cristalizar um quadro já dominante de injustiça social. Apesar disto, traz instrumentos compensatórios para diminuir as desigualdades ou, menos pretensiosamente, diminuir o contingente dos erráticos miseráveis que vagueiam pelas ruas deste pais, chamando a comunidade, a sociedade em geral e transferindo-lhes parcela de responsabilidade. Mas, se a lei existe para regular as interações sociais, deve apontar para aquilo que deve ser. Em outras palavras: a lei regulamenta o presente, com as experiências que colheu no passado, para direcionar o futuro de uma sociedade que se pretenda justa, fraterna e igualitário,

Diga-se que a tarefa da lei não se exaure na sua publicação ou nas modificações que conhece ao longo do tempo. A lei é fruto da soma das vontades de um povo e é a ele, sobretudo a ele, que se destina a construção do futuro, balizado pela lei. O reconhecimento eventual do desacerto, da i^lzufiilidade ou injustiça da lei é que a torna letra morta e consagra a popular (talvez, a mais sábia) divisão entre as leis vigentes, entre aquelas que pegam e aquelas que não pegam. O Estatuto da Criança e do Adolescente, aos olhos daqueles que andam nas ruas e trombam - e acostumaramse a trombar - com as tantas crianças nos semáforos, nos viadutos, nas praças e quedam-se a pensar onde estariam os pais dessas crianças, ainda não pegou. A solução da lei não tomou de assalto as ruas, ainda não produziu a diferença que se extrai de sua dicção.

Em meio a tanto caos, valerá a lembrança de Sêneca: ninguém devolverá teus anos, ninguém te fará voltar a fi mesmo. Os anos perdidos de tantas crianças se foram, os tempos de desobrigo já estão na história de cada uma dessas crianças. O futuro é hoje e, como sempre, vem tarde.

CONSTIÇÃO DA REPÚBLICA FEDERATIVA DO BRASIL de 24.01.1967 e de 1988.

ESPÍNOLA, E. A farntlia no direito civil brasileiro. Rio de Janeiro, 1954.

ESTATUTO DA CRIANÇA E DO ADOLESCENTE, Lci n 8.069, 13.07.1990.

EVANS-PRITCHARD. African Political Systern. London, 1940. 
FIRTH, R. W. Elernents of social orpanization. London, 1951.

GOMES, O. Direito de farnflia. Rio de Janeiro, 1968.

KROEBER, A. L. et ai. Organização social. In LARAIA, R. B. Textos Básicos de Ciências Sociais. Rio de Janeiro, 1969.

LEACH, E. R. Rethinking antropology, London, 1961.

LÉVI-STRAUSS, C. Antropologie structurale. Paris, 1958.

LOWIE, R. H. Methode der ethnologie. 1911.

MALINOWSKI B. A scientific theory of cultura and other lissas. 1949.

Ml'LENNAN. Prirnitive rnamage. 1865.
MONTEIRO, W. B. Curso de diríeis civil. direito de família. 1O ${ }^{a}$ Ed., São Paulo, 1971, V. 2.

MURDOCK, G. P. ad. Social structure in Southeast Asia. New ore, 1960.

PEREIRA, C. M. S. Instituições cite direito civil. Rio de Janeiro, 1961 - 1972, V. 5.

PONTES DE MIRANDA, F. C. Tratado de direito de família. 3a Eh., São Paulo, 1947, V. 3.

RADCLIFFE, B. A. R. The mother's brother in Soutb Afiica S. Afr: J.Sci,21, 1924.

WALD, A. ed. Curso de direito civil brasileiro. $2^{a}$ Ed., São Paulo, 1969 - 1970 V. 5.

recebido em: 08/06194 aprovado em: 13/10/94 